\title{
How non-operator farmland owners can promote land stewardship
}

More than half of U.S. farmland is not farmed by its owner. The high rate of tenancy typically gets major attention in analyses of the soil conservation situation. It is often assumed that rented land is not protected as well as when it is owned by the farmer. The usual reason given is that a non-operating owner may care more about getting an immediate return and not be so concerned about soil conservation as an owner-operator.

But the issue has another side. Landowners who rent out their land may be very interested in soil conservation and environmental protection but suspect that their land is not being cared for as well as it could be. However, they may think there is nothing they can do about it and that they are limited by their tenants' priorities and dedication. But alternatives are available.

True, an uncooperative tenant can frustrate every move towards better stewardship. But many tenants will respond positively to appropriate initiatives by the owner if they are based on informed agreement and a spirit of partnership and cooperation.

A fully developed stewardship program will have several components: permanent land structures (possibly), crop diversification and rotation, integration of livestock and crop production, and reduction in the use of agricultural chemicals.

Unless the land is very level, it probably will need water diversion terraces and grassed waterways. Installing these structures can begin with a meeting of the tenant, owner, and Soil Conservation Service technician. Major conservation work should be spread out over several years, so that the tenant is not overwhelmed by special tillage and other management requirements. This also maximizes access to limited SCS funds that are awarded annually and reduces the risk that the entire grassed waterway system will be damaged by bad weather before the cover is established. Eroding land that will not get terraces and waterways immediately can be placed in the setaside program or seeded to a soil conserving crop such as alfalfa. In deciding the size and layout of the structures, the tenant's convenience should be an important consideration. This may dictate large, parallel terraces that are suitable for large equipment and that do not have bothersome point rows, even though such terraces are more expensive. Beginning the farm care plan with soil conservation, which in any case is a natural place to start, has the additional advantage of assuring compliance with new federal requirements for eligibility in subsidy programs, which specify that the farm must develop a conservation plan by 1990 and implement it by 1995 .

Another important erosion control technique is crop diver-

Jim Bender is an organic farmer near Weeping Water, NE. sification and rotation. These also are beneficial because they allow an eventual reduction in pesticide use. Rotations may include some crops that are less profitable than those currently grown. The owner can encourage a tenant to grow these crops by increasing the tenant's crop share or reducing the cash rent.

Rotations can be particularly advantageous when integrated with livestock production, especially rotations involving soil conserving, nitrogen fixing legumes that can be consumed by livestock. Livestock also benefit both owner and tenant by allowing an income to be obtained from rough land that otherwise would be idle and from highly erodible land seeded to grass for soil conservation. However, there is a trend away from mixed crop-livestock farming, and tenants may not wish to have livestock. The owner can help overcome this reluctance by paying for the fencing, water supply and handling facilities. Also, the rent should take account of the labor the tenant put into installing these investments, so that their cost is shared equitably if the tenant leaves the farm before the end of their useful life.

After a rotation is established, the tenant can be encouraged to experiment with reductions in insecticide applications. The landowner must be willing to absorb part of the temporary loss of revenue that might result. Reducing herbicides is a more ambitious step, requiring considerable dedication and perseverance on the part of the tenant. The landlord should adjust the rent to compensate the tenant for the extra work and management, taking account also of the reduced expenses for chemicals. Finally, mixed crop/livestock production also permits reduction in fertilizer applications through manure spreading, which should also be reflected in the lease.

Beyond the specific choices that must be made regarding the best production system, the spirit underlying the owner-tenant relationship is a critical element. The landowner and tenant should share an interest in stewardship and consider themselves as partners in pursuing that goal. A share rental arrangement reflects this idea better than cash rental. Fostering stewardship can be complicated if the owner hires a farm management service, unless the manager shares the owner's enthusiasm.

A good way to sustain the interest of both owner and tenant is through on-farm research. The owner could also subsidize the tenant's education in alternative agriculture, such as by paying for subscriptions to appropriate magazines or by partially supporting the costs of attending relevant seminars and conferences. The owner should also make regular visits and calls to maintain good communication with the tenant. Demonstrated interest by the owner is the key to a successful owner/ tenant partnership for stewardship. After all, the tenant can hardly be expected to take more interest in caring for the land than does the person who owns it.

American Journal of Alternative Agriculture 